\title{
Element Distribution in Silicon Refining: Thermodynamic Model and Industrial Measurements
}

\author{
MARI K. NÆSS, ${ }^{1,3}$ IDA KERO, ${ }^{1}$ GABRIELLA TRANELL,${ }^{1}$ KAI TANG,${ }^{2}$ \\ and HALVARD TVEIT ${ }^{1}$ \\ 1.-Department of Materials Science and Engineering, Norwegian University of Science and \\ Technology (NTNU), Alfred Getz vei 2, 7491 Trondheim, Norway. 2.-SINTEF Materials and \\ Chemistry, 7465 Trondheim, Norway. 3.—e-mail: mari.k.naess@sintef.no
}

To establish an overview of impurity elemental distribution among silicon, slag, and gas/fume in the refining process of metallurgical grade silicon (MG$\mathrm{Si}$ ), an industrial measurement campaign was performed at the Elkem Salten MG-Si plant in Norway. Samples of in- and outgoing mass streams, i.e., tapped $\mathrm{Si}$, flux and cooling materials, refined $\mathrm{Si}$, slag, and fume, were analyzed by high-resolution inductively coupled plasma mass spectrometry (HR-ICP-MS), with respect to 62 elements. The elemental distributions were calculated and the experimental data compared with equilibrium estimations based on commercial and proprietary, published databases and carried out using the ChemSheet software. The results are discussed in terms of boiling temperatures, vapor pressures, redox potentials, and activities of the elements. These model calculations indicate a need for expanded databases with more and reliable thermodynamic data for trace elements in general and fume constituents in particular.

\section{INTRODUCTION}

Metallurgical grade silicon (MG-Si) is produced in the electric arc furnace followed by an oxidative ladle refining (OLR) step. These two process steps are illustrated in Fig. 1. The OLR is primarily aimed at removing $\mathrm{Ca}$ and $\mathrm{Al}$ from the tapped silicon and involves purging the melt with an airoxygen mixture, preferentially oxidizing the impurities into a slag phase. ${ }^{1}$

Silica fume $\left(\mathrm{SiO}_{2}\right)$ will be generated at the furnace top by combustion of exhaust gas containing $\mathrm{SiO}_{(\mathrm{g})}$. The silica from the furnace top is usually collected and sold as a product for many applications. ${ }^{2}$ Silica fume will also form whenever liquid silicon is in contact with oxygen, as in the OLR process. ${ }^{3,4}$ The fume is not only a source of silicon loss, but it is also harmful to the health of the workers at the silicon plant when inhaled. ${ }^{5-7}$ For that reason, the use of dust masks are mandatory in exposed areas in most silicon plants in Norway. In addition to $\mathrm{SiO}_{2}$, the exhaust gas from the furnace contains traces of other elements originating from impurities in charge materials, electrodes, etc. ${ }^{8,9}$ The fume from the OLR process, which is one of the main sources of fugitive emissions in the plant, in contrast to the furnace exhaust gas, is often only partly vented and seldom analyzed.

The production of MG-Si and other metals is regulated by strict environmental laws, which are continuously upgraded in terms of adjusting the emission limits and requiring higher accuracy in the emission reporting. It is therefore important for silicon producers to be able to account for the pathway of individual trace elements, in particular those of a toxic nature, throughout every step of the production.

In this article, industrial measurements and thermodynamic considerations are used to provide an overview of the elemental distribution between phases in the silicon refining process. This information will constitute a basis for further work aimed to quantify and limit the total emission rate. In a separate publication, ${ }^{10}$ various sources of error and uncertainties were evaluated with respect to the industrial ability to make accurate estimations of the fugitive emissions from the silicon refining process. 


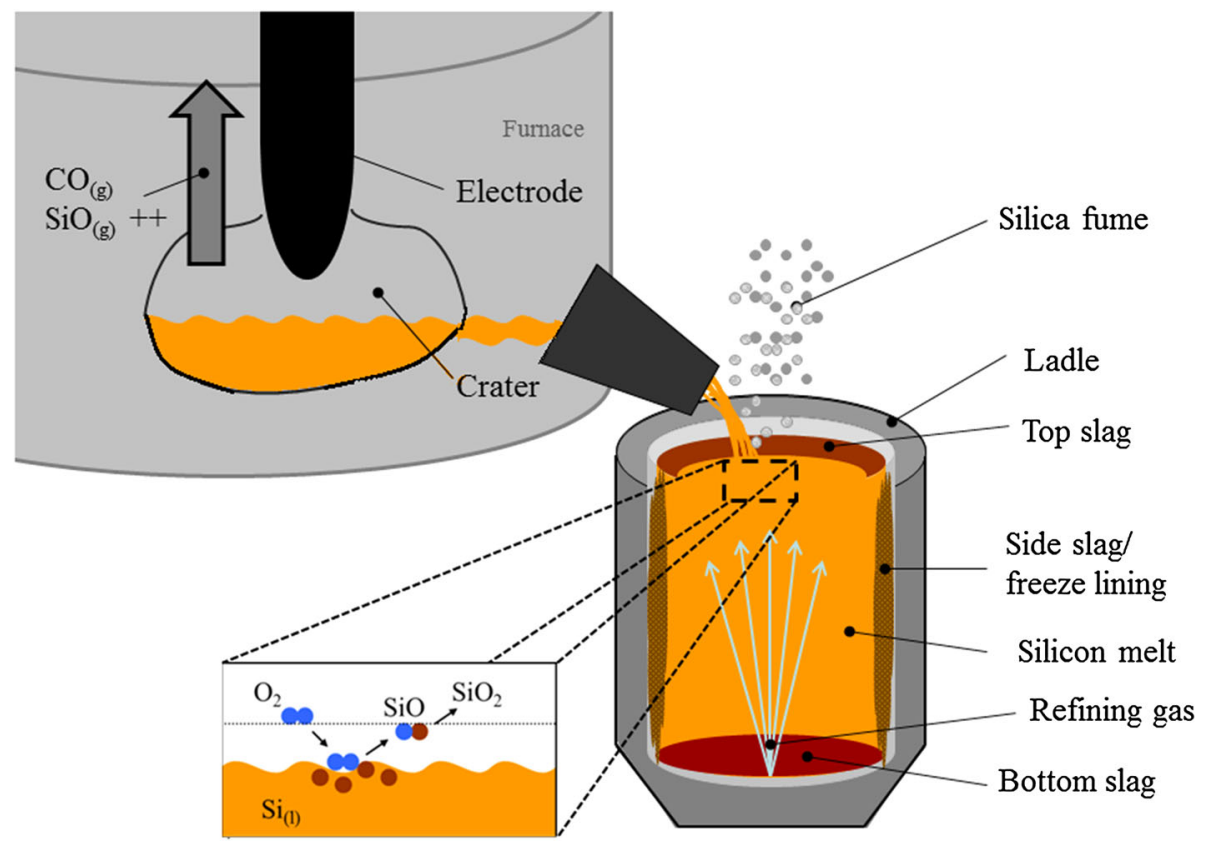

Fig. 1. Schematic of the phases present in the furnace and ladle. The oxidation mechanism at the Si surface is also illustrated. ${ }^{3}$

\section{The Furnace Fume and the Boiling Point Model}

The elemental distribution in the electric arc silicon furnace has been studied by Garcia and Myrhaug, ${ }^{8}$ and some of the results are illustrated in Fig. 2. A so-called "boiling-point-model" was developed by Myrhaug and Tveit ${ }^{9}$ for the elemental distribution in a ferrosilicon furnace to predict the trends in distribution of elements between the outgoing phases of the furnace. Although the fundamental principles of their work may be applicable to the OLR as well, there are some differences between the furnace and the ladle that may alter the behavior of certain elements. The boiling temperatures $^{11}$ of all elements included in this work are plotted in Fig. 3, along with the process temperature of the ladle. The operation temperature of the furnace $\left(\sim 2,000^{\circ} \mathrm{C}\right)$ is considerably higher than that of the ladle $\left(\sim 1,500^{\circ} \mathrm{C}\right)$, which is likely to influence the volatility of elements and compounds. The reducing conditions of the furnace may also result in somewhat different elemental behavior than in the oxygen-purged ladle.

According to the boiling point model ${ }^{9}$ elements with boiling temperatures higher than the process temperature will preferentially stay in the condensed phase while elements with boiling temperatures below the process temperature should go off as fume or gas. This is on the condition that they are present in elemental form. For elements present as oxides or other compounds, the boiling temperature of the compound will be decisive. Elements with vapor pressure higher than $\mathrm{Si}$ are also likely to report preferentially to the fume. ${ }^{12}$ The boiling temperatures presented in Fig. 3 are for the pure elements; thus, the boiling point model assumes an ideal behavior of the elements. It is, as such, a crude estimation of the pathways of the elements.

\section{The Refining Process and the Oxidation Potential}

Silicon from the furnace is tapped into a ladle together with a small amount of slag. The OLR treatment consists of purging a mixture of air and oxygen through the melt from a nozzle in the bottom of the ladle (see Fig. 1). The oxygen in the refining gas will react with the silicon to form silica slag at the gas bubble/melt interface via the reaction:

$$
\mathrm{Si}_{(\mathrm{l})}+\mathrm{O}_{2(\mathrm{~g})} \rightarrow \mathrm{SiO}_{2(1 / \mathrm{s})}
$$

The silica at the bubble-silicon interface will further react with the main impurities aluminum $(\mathrm{Al})$ and calcium $(\mathrm{Ca})$ via the exchange reactions (1):

$$
\begin{gathered}
4 \underline{\mathrm{Al}}+3 \mathrm{SiO}_{2} \leftrightarrow 3 \underline{\mathrm{Si}}+2 \mathrm{Al}_{2} \mathrm{O}_{3} \\
2 \underline{\mathrm{Ca}}+\mathrm{SiO}_{2} \leftrightarrow \underline{\mathrm{Si}}+2 \mathrm{CaO}
\end{gathered}
$$

The purging of the gas stirs the melt, pushing the produced top slag toward the periphery of the ladle in the form of a ring, leaving the Si in the vortex free of slag. The slag will change composition over the refining cycle and, thus, establish equilibrium with the silicon at the silicon-slag interface.

A sample of the tapped $\mathrm{Si}$ is collected and tested for its $\mathrm{Al}$ and $\mathrm{Ca}$ concentration. From this information, the exact amount of flux material is calculated. The flux consists of silica/quarts sand and is 


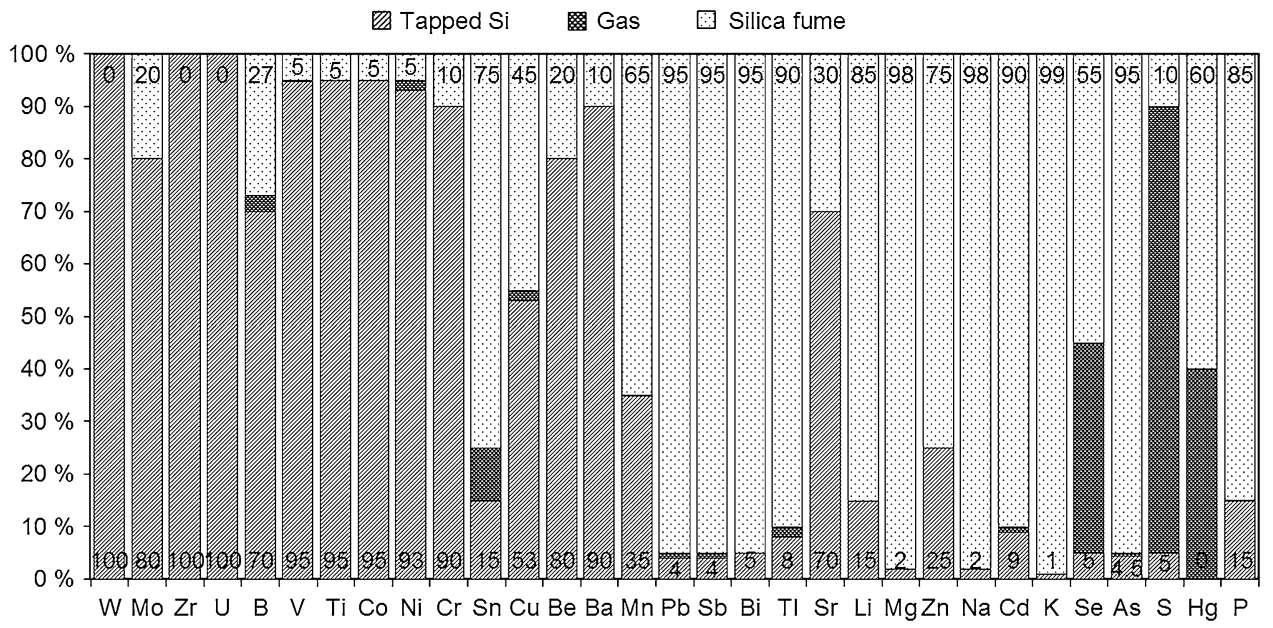

Fig. 2. Distribution of elements in the mass flows out of the furnace: tapped $\mathrm{Si}$, silica fume from the furnace top, and exhaust gas. The distribution coefficients for the tapped silicon and the condensed silica fume are displayed in each column, at the base and the top, respectively. All values are taken from Garcia and Myrhaug. ${ }^{8}$

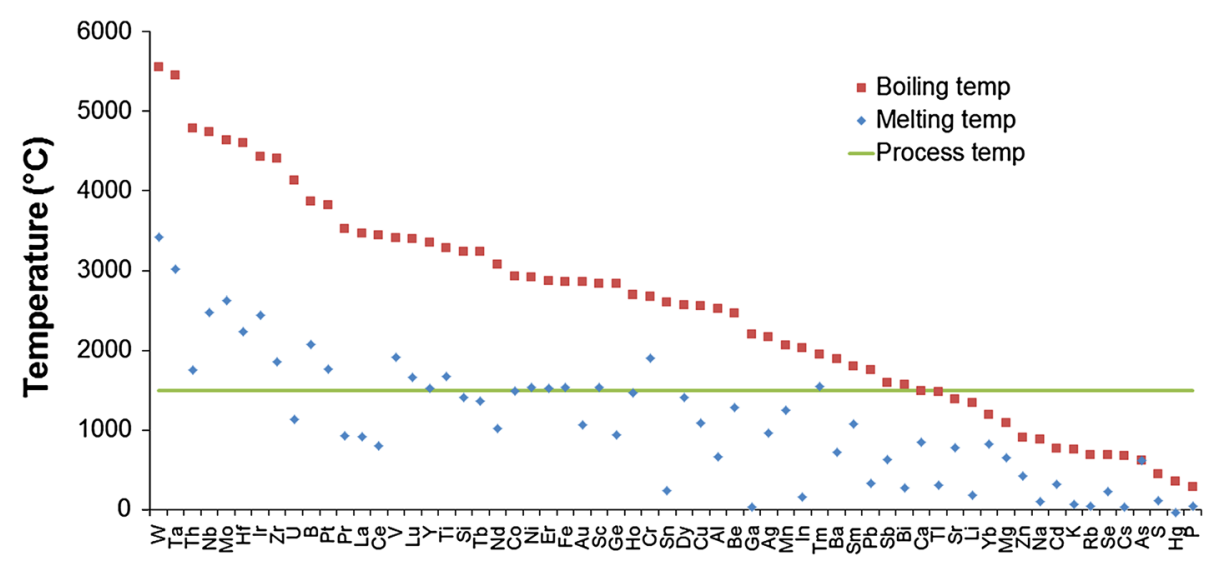

Fig. 3. The melting and boiling temperatures of the elements plotted with the process temperature of the ladle $\left(\sim 1,500^{\circ} \mathrm{C}\right)$.

added to get the desired slag composition and, thus, the preferred silicon composition. Cooling material is added to adjust the temperature of the product before casting, and the amount is determined by monitoring the temperature of the melt. The cooling material consists mainly of fines from the crushing of the Si product; thus, it will have approximately the same composition as the refined product. When the refining is finished, which it usually is by the time the ladle is full, the $\mathrm{Si}$ is cast and the remaining slag is removed from the ladle.

A schematic overview of the phases present in the ladle is shown in Fig. 1, including the mechanism for the formation of fume. The fumes derive from the partial oxidation of silicon at the surface, resulting in formation of $\mathrm{SiO}$ gas. As this gas leaves the surface, it is oxidized further to become amorphous $\mathrm{SiO}_{2}$ fume. The quantitative and qualitative measurements of the fumes as well as the characterization of fume particles with respect to particle size distribution are reported in earlier work. ${ }^{2}$ In addition to silicon, other elements may also be vaporized or oxidized and, thus, follow the $\mathrm{SiO}$ gas to end up in the fume from the ladle.

The oxidation potential of each element may be used, in combination with the boiling point of each element and their oxides, to understand the pathway through the OLR process. The relative redox potential for the element, compared with silicon/ silica, and its activity coefficient in the liquid metal decides the direction of this equilibrium reaction. This information is illustrated in Fig. 4, and Eq. 4 outlines the general exchange reaction for the refining of elements from the silicon melt:

$$
\frac{x}{y} \underline{\mathrm{Me}}+\frac{1}{2} \mathrm{SiO}_{2} \leftrightarrow \frac{1}{y} \mathrm{Me}_{x} \mathrm{O}_{y}+\frac{1}{2} \underline{\mathrm{Si}}
$$

where Me represents an arbitrary impurity element in $\mathrm{Si}$ and a bar under the element abbreviation indicates its elemental presence in the silicon melt.

In an ideal description of the system, elements with higher Gibbs free energy of oxidation than silicon have two possible paths: silicon or fume. The elements with 
lower Gibbs free energy of oxide formation will oxidize and report to the slag. With deviation from ideality, elemental behaviors will be altered. Although many of the binary Si-Me alloy systems are thermodynamically described, the element distribution among a complex slag, a silicon alloy, and fume has, to date, not been measured and no attempt to predict it has been made. ${ }^{3,9,13-15}$ In the present study, the elemental distribution of this complex system is experimentally determined and compared with previously available data through the use of modern databases.

\section{METHOD}

\section{Industrial Sampling and Analysis}

A comprehensive industrial measurement campaign was performed on a 35-MW furnace at the
Elkem Salten MG-Si plant in Norway. The furnace produces 25,000 tons of high-silicon alloy per year, and it is one of three furnaces at the plant. Samples of silicon, slag, and fume were collected, as illustrated in Fig. 5, from eight different refining ladles with a standard purge gas mixture and flow rate conditions during 3 days. At the time of sampling, the temperature in the $\mathrm{Si}$ was in the range of $1,446^{\circ} \mathrm{C}-1,677^{\circ} \mathrm{C}$. Samples from the tapped $\mathrm{Si}$, as tapped into the ladle, were taken from the tapping jet. A sample of the fully refined Si was collected just before casting. Slag samples were gathered from the bottom of the ladle, from the side (freeze lining), and from the top layer. Fume samples were collected with a "cold finger" (a water-cooled copper tube) placed in the exhaust gas channel during tapping. Samples, sampling times, and conditions are detailed in Table I.

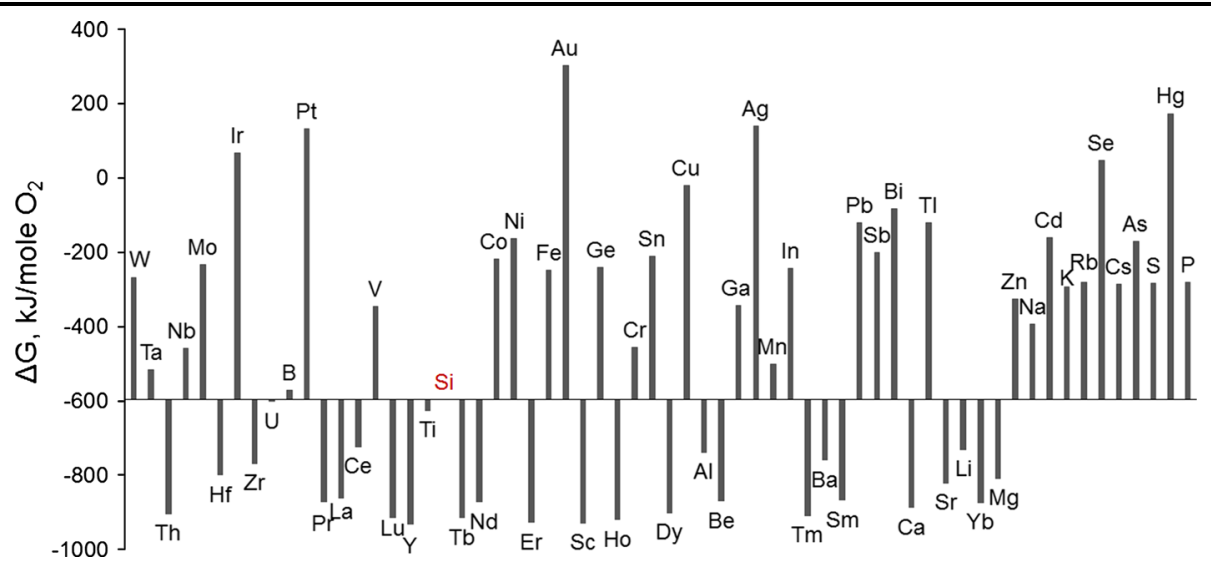

Fig. 4. Gibbs free energy of oxidation of silicon and all the elements discussed in this article. The energies are calculated for one mole of oxygen, and the most stable oxides are used. All oxides below silicon are more easily oxidized to their corresponding oxides than silicon to silica.

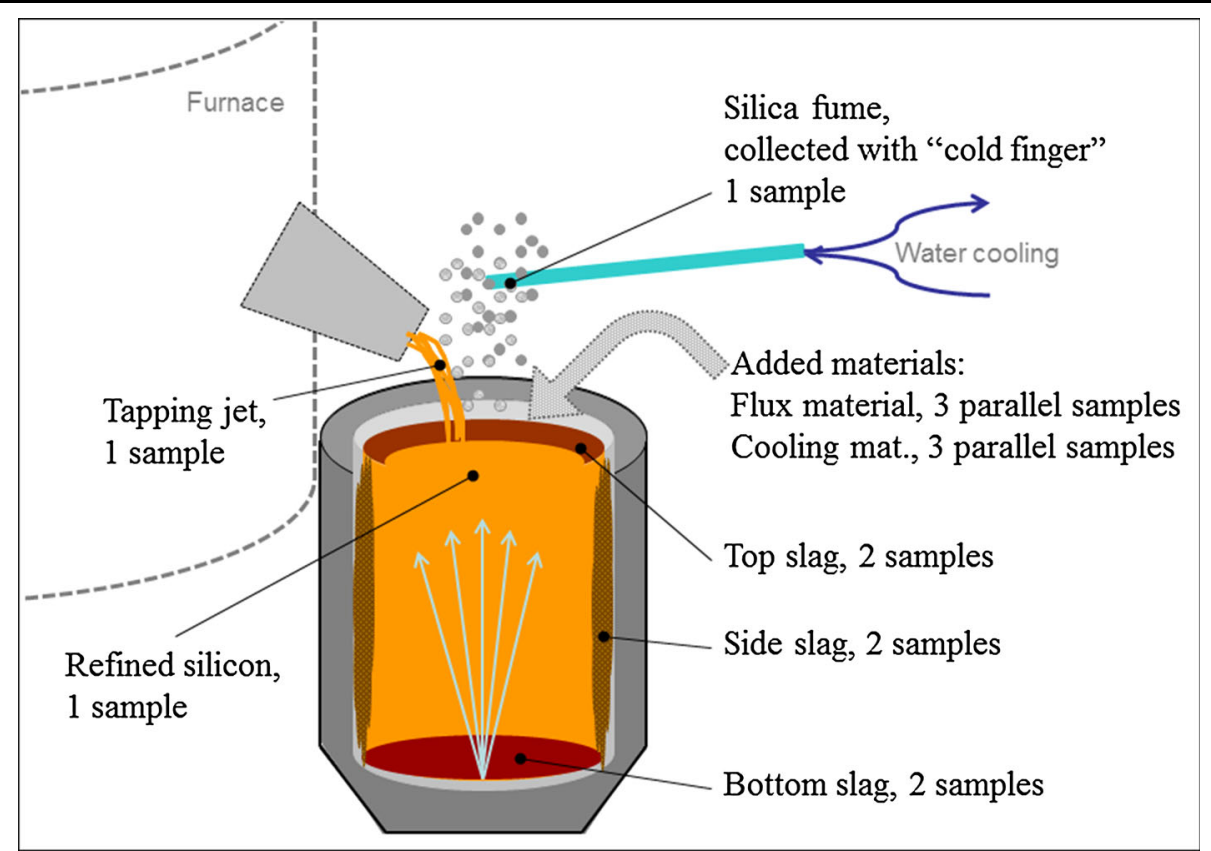

Fig. 5. Sketch of the sample collection procedure in the ladle. 
Table I. Overview of samples taken and their respective conditions

\begin{tabular}{lcc}
\hline Sample & Taken when & \multicolumn{1}{c}{ T in melt $\left({ }^{\circ} \mathbf{C}\right)$} \\
\cline { 3 - 4 } Jet & Collected early in the tapping process. & $1,551-1,677$ \\
Fume & Collected early in the tapping process & - \\
Refined & Right before casting & $1,446-1,506$ \\
Slag & After casting & - \\
Cooling material & Three parallels from the batch & - \\
Flux material & From three different bags & - \\
\hline
\end{tabular}

Three parallel samples of the added cooling and flux materials were taken. The amount of added flux material varied from $0 \mathrm{~kg}$ to $320 \mathrm{~kg}$ and cooling material from $0 \mathrm{~kg}$ to $250 \mathrm{~kg}$ per ladle. A total of 105 samples of different phases and material streams were collected and analyzed by inductively coupled plasma mass spectrometry (ICP-MS) (Element2 from Thermo Electronics). The solid bulk samples were crushed to a powder and dissolved in acids prior to ICP-MS analysis. The sample preparation process is detailed elsewhere. ${ }^{10}$

All samples were analyzed by ICP-MS with respect to 62 elements, as listed in Table II.

When specific elemental contamination was observed in individual samples, these elements were singled out and treated accordingly. Alas, $\mathrm{Cu}$ contamination was found to afflict all the fume samples taken with the "cold finger" (chips of the soft copper metal were discovered in the samples). To calculate the overall distribution of $\mathrm{Cu}$, a recovery rate of $100 \%$ was assumed and any conclusions on the $\mathrm{Cu}$ distribution are based on this assumption.

Recovery calculations have been carried out according to:

$$
\% R_{i}=\frac{\mathrm{m}_{i, \mathrm{out}}}{\mathrm{m}_{i, \mathrm{in}}} \cdot 100
$$

where $\% R_{i}$ is the recovery in $\%$, and $m_{i \text {,out }}$ and $m_{i \text {,in }}$ are the total masses of element $i$ going out of and into the ladle, respectively. Outgoing mass flow is the sum of the refined $\mathrm{Si}$, the slag, and the fume. Ingoing mass flow is the sum of the tapped $\mathrm{Si}$, the cooling material, and the flux material.

The experimental distribution ratio between the condensed phases (slag and silicon) was calculated for elements that could not be modeled thermochemically as a result of a lack of data in databases, according to:

$$
L_{\mathrm{Me}}^{\exp }=\frac{w_{\mathrm{El}-\mathrm{Si}}}{w_{\mathrm{ElO}_{x}-\text { slag }}}
$$

where $L_{\mathrm{El}}^{\exp }$ is the experimental distribution ratio, $w_{\mathrm{El}-\mathrm{Si}}$ is the weight percent of the element in the refined silicon alloy, and $w_{\mathrm{ElO}_{x} \text {-slag }}$ is the weight percent of the element oxide in the slag phase.

\section{Thermochemical Simulation}

Equilibrium calculations for the distribution of 19 impurity elements in liquid silicon and gas (fume) and 17 elements in molten slag, as well as their stoichiometric pure compounds, have been carried out using the ChemSheet Add-In Gibbs energy minimizer in the Microsoft Excel (Microsoft Corporation, Redmond, WA) spreadsheet. ${ }^{16}$ A proprietary thermochemical database ${ }^{17,18}$ has been developed for this purpose, and the 19 elements chosen for the model are the best described elements in the system, with the most reliable thermodynamic data. Thermodynamic descriptions of liquid Si-based Ag-Al-B-Ca-Cd$\mathrm{Co}-\mathrm{Cr}-\mathrm{Cu}-\mathrm{Fe}-\mathrm{K}-\mathrm{Mg}-\mathrm{Mn}-\mathrm{Na}-\mathrm{Ni}-\mathrm{O}-\mathrm{P}-\mathrm{Pb}-\mathrm{Ti}-\mathrm{V}-\mathrm{Zn}$ melts have been taken from previous work. ${ }^{18}$

Thermodynamic properties of the pure compounds were taken from the FACT pure substance database. ${ }^{19}$ The cell model has been selected for the description of the non-ideal behavior of molten oxide phase containing $\mathrm{P}_{2} \mathrm{O}_{5}-\mathrm{SiO}_{2}-\mathrm{TiO}_{2}-\mathrm{Al}_{2} \mathrm{O}_{3}-\mathrm{B}_{2} \mathrm{O}_{3}-\mathrm{Cr}_{2} \mathrm{O}_{3}$ $\mathrm{Ti}_{2} \mathrm{O}_{3}$-CaO-FeO-MgO-MnO-NiO-PbO-ZnO-Ag ${ }_{2} \mathrm{O}-$ $\mathrm{Cu}_{2} \mathrm{O}-\mathrm{K}_{2} \mathrm{O}-\mathrm{Na}_{2} \mathrm{O}$. The model parameters for the $\mathrm{P}_{2} \mathrm{O}_{5}-\mathrm{SiO}_{2}-\mathrm{TiO}_{2}-\mathrm{Al}_{2} \mathrm{O}_{3}-\mathrm{B}_{2} \mathrm{O}_{3}-\mathrm{Cr}_{2} \mathrm{O}_{3}-\mathrm{Ti}_{2} \mathrm{O}_{3}-\mathrm{CaO}-\mathrm{FeO}-$ $\mathrm{MgO}-\mathrm{MnO}$ subsystem were taken from the publication of Gaye et al. ${ }^{20}$ For those of $\mathrm{B}_{2} \mathrm{O}_{3}, \mathrm{NiO}, \mathrm{PbO}$, $\mathrm{ZnO}, \mathrm{Ag}_{2} \mathrm{O}, \mathrm{Cu}_{2} \mathrm{O}, \mathrm{K}_{2} \mathrm{O}$ and $\mathrm{Na}_{2} \mathrm{O}$ in the molten slag phase, the model parameters were estimated from proprietary database ${ }^{17}$ in order to estimate the distribution. Since these impurities in liquid silicon are in the range of dilute $(<1 \%)$, such a treatment will not bring significant error in equilibrium calculations.

Measured elemental concentrations are presented in Table III, and the measured values for the tapped silicon were used for the simulations. The model calculations have been carried out under the following assumptions:

- No concentration gradients exist in the liquid silicon and slag phases.

- Reactions between metal/slag/gas go completely to equilibrium.

- The composition of the tapped silicon is constant.

- The measured average refining temperatures are used in the simulations.

- The oxidation of silicon metal by the bottom airblowing and on the surface of liquid metal during the ladle refining are accounted for in the simulations. 
Table II. Concentration of elements, ordered by boiling point, ${ }^{11}$ in the outgoing phases of the ladle ${ }^{a}$

\begin{tabular}{|c|c|c|c|c|}
\hline Element & Fume (ppm) & Slag (ppm) & Refined silicon (ppm) & $\gamma_{M e-S i}$ \\
\hline $\mathrm{W}$ & $<5$ & $<10$ & $0.5-5$ & \\
\hline $\mathrm{Ta}$ & $<0.5$ & $0.1-0.5$ & $0.1-0.5$ & \\
\hline Th & $<5$ & $0.5-5$ & $1-5$ & \\
\hline $\mathrm{Nb}$ & $<5$ & $1-5$ & $1-5$ & \\
\hline Mo & $0.1-5$ & $1-5$ & $1-5$ & $1.9 \cdot 10^{-3}$ \\
\hline $\mathrm{Hf}$ & $<5$ & $1-5$ & $1-5$ & \\
\hline Ir & $\mathrm{b}$ & $\mathrm{b}$ & $\mathrm{b}$ & \\
\hline $\mathrm{Zr}$ & $<500$ & $10-100$ & $100-500$ & $6.7 \cdot 10^{-6}$ \\
\hline $\mathrm{U}$ & $<5$ & $0.1-5$ & $1-5$ & \\
\hline$B$ & $10-50$ & $10-50$ & $10-50$ & 2.1 \\
\hline $\mathrm{Pt}$ & $\mathrm{b}$ & $\mathrm{b}$ & $\mathrm{b}$ & \\
\hline $\operatorname{Pr}$ & $<5$ & $0.1-5$ & $1-5$ & \\
\hline $\mathrm{La}$ & $<10$ & $0.5-10$ & $5-50$ & \\
\hline $\mathrm{Ce}$ & $<50$ & $1-50$ & $10-50$ & \\
\hline$V$ & $<50$ & $5-50$ & $10-50$ & $3.7 \cdot 10^{-4}$ \\
\hline $\mathrm{Lu}$ & $<0.5$ & $0.01-1$ & $0.01-0.1$ & \\
\hline $\mathrm{Y}$ & $<10$ & $<50$ & $0.5-10$ & $5.7 \cdot 10^{-5}$ \\
\hline$T i$ & $<1,000$ & $100-1,000$ & $500-1,000$ & $2.5 \cdot 10^{-5}$ \\
\hline $\mathrm{Tb}$ & $<0.5$ & $0.1-0.5$ & $0.1-0.5$ & \\
\hline $\mathrm{Nd}$ & $<10$ & $0.5-10$ & $5-50$ & \\
\hline Co & $<10$ & $1-10$ & $5-10$ & 0.013 \\
\hline$N i$ & $1-50$ & $1-50$ & $10-50$ & $2.9 \cdot 10^{-7}$ \\
\hline $\mathrm{Er}$ & $<5$ & $0.1-5$ & $0.1-5$ & \\
\hline $\mathrm{Fe}$ & $<10^{5}$ & $1,000-5 \bullet 10^{4}$ & $10^{4}-5 \bullet 10^{4}$ & $7.7 \cdot 10^{-4}$ \\
\hline $\mathrm{Au}$ & $0.001-0.01$ & $0.001-0.005$ & $0.001-0.005$ & $1.8 \cdot 10^{-3}$ \\
\hline $\mathrm{Sc}$ & $<5$ & $0.5-5$ & $1-5$ & \\
\hline $\mathrm{Ge}$ & $0.1-5$ & $0.1-5$ & $1-5$ & 1.5 \\
\hline Но & $<0.5$ & $0.1-1$ & $0.1-0.5$ & \\
\hline $\mathrm{Cr}$ & $5-50$ & $10-100$ & $10-100$ & $6.7 \cdot 10^{-4}$ \\
\hline Sn & $<5$ & $0.01-0.5$ & $0.1-0.5$ & 5.5 \\
\hline Dy & $<5$ & $0.1-5$ & $0.5-5$ & \\
\hline $\mathrm{Cu}$ & $100-1,000$ & $5-50$ & $10-50$ & 0.72 \\
\hline$A l$ & $1,000-10^{4}$ & $5,000-5 \bullet 10^{4}$ & $1,000-5,000$ & 0.45 \\
\hline $\mathrm{Be}$ & $0.01-5$ & $1-50$ & $0.01-0.5$ & \\
\hline $\mathrm{Ga}$ & $0.1-5$ & $0.05-0.5$ & $0.1-1$ & 1.4 \\
\hline$A g$ & $1-500$ & $\mathrm{~b}$ & $\mathrm{~b}$ & 1.4 \\
\hline$M n$ & $5-500$ & $1-500$ & $50-100$ & $4.6 \cdot 10^{-3}$ \\
\hline In & $0.001-0.01$ & $\mathrm{~b}$ & $\mathrm{~b}$ & 3.9 \\
\hline $\mathrm{Tm}$ & $<0.5$ & $0.01-0.5$ & $0.05-0.5$ & \\
\hline $\mathrm{Ba}$ & $<500$ & $10-5,000$ & $<5$ & \\
\hline $\mathrm{Sm}$ & $<5$ & $0.1-5$ & $0.5-5$ & \\
\hline $\mathrm{Pb}$ & $0.5-50$ & $<1$ & $0.01-0.5$ & 29 \\
\hline $\mathrm{Sb}$ & $<50$ & $0.01-0.1$ & $0.01-0.1$ & 4.4 \\
\hline $\mathrm{Bi}$ & $0.01-0.5$ & b & $\mathrm{b}$ & 26 \\
\hline$C a$ & $500-5,000$ & $<5 \bullet 10^{4}$ & $10-100$ & $4.1 \cdot 10^{-3}$ \\
\hline $\mathrm{Tl}$ & $<0.5$ & $\mathrm{~b}$ & $\mathrm{~b}$ & \\
\hline $\mathrm{Sr}$ & $5-100$ & $10-1,000$ & $<5$ & \\
\hline $\mathrm{Li}$ & $5-50$ & 1-50 & $0.05-0.5$ & 0.017 \\
\hline $\mathrm{Yb}$ & $0.05-1$ & $0.1-5$ & $0.1-1$ & \\
\hline$M g$ & $100-5,000$ & $5-100$ & $1-10$ & 0.28 \\
\hline$Z n$ & $10-500$ & $<10$ & $1-10$ & 1.9 \\
\hline $\mathrm{Na}$ & $100-1000$ & $<500$ & $\mathrm{~b}$ & 0.018 \\
\hline$C d$ & $<50$ & $\mathrm{~b}$ & $\mathrm{~b}$ & 0.73 \\
\hline$K$ & $500-5,000$ & $<1,000$ & $\mathrm{~b}$ & 510 \\
\hline $\mathrm{Rb}$ & $1-50$ & $<5$ & $\mathrm{~b}$ & \\
\hline $\mathrm{Se}$ & $0.05-5$ & $\mathrm{~b}$ & $\mathrm{~b}$ & \\
\hline $\mathrm{Cs}$ & $\mathrm{b}$ & $\mathrm{b}$ & $\mathrm{b}$ & \\
\hline As & $0.1-5$ & $0.1-0.5$ & $0.1-0.5$ & 4.4 \\
\hline $\mathrm{S}$ & $\mathrm{b}$ & $\mathrm{b}$ & $\mathrm{b}$ & 0.25 \\
\hline $\mathrm{Hg}$ & $\mathrm{b}$ & $\mathrm{b}$ & $\mathrm{b}$ & \\
\hline$P$ & $<1,000$ & $5-50$ & $10-100$ & 3.1 \\
\hline
\end{tabular}

${ }^{a}$ Slag values are the averages of three slag phases. Activity coefficients are from the literature ${ }^{16}$ at $1,600^{\circ} \mathrm{C}$, and there is an assumed dilute solution. Elements included in the thermochemical model are written in Italic ${ }^{\mathrm{b}}$ Concentration is lower than the IDL. 
ChemSage simulations were used to calculate the amount of $\mathrm{O}_{2}$ in the OLR process. The simulations indicate that the total amount of oxygen is much higher than the $\mathrm{O}_{2}$ introduced by bottom blowing can supply. The surface oxidation in ambient air is clearly an important source of oxygen. The element distribution among the fume, silicon, and slag phases were calculated using the spreadsheet program with the basic input parameters presented in Table III.

\section{RESULTS AND DISCUSSION}

The activity coefficients of the elements in a dilute, binary, liquid silicon alloy are given in Table II, along with the measured concentration ranges of each element in the refined silicon, the slag, and the fume phases. The concentration values given in Table II are calculated minimum and maximum values; based on all sources of error from sampling to ICP-MS analysis. The sources of error, combined errors, and their calculations are discussed in detail in a separate publication. ${ }^{10}$

The ICP-MS data for some elements had large analytical errors compared with the majority of

Table III. Input parameters used for the
thermochemical model
thermochemical model

\begin{tabular}{|c|c|}
\hline Parameter (unit) & Value \\
\hline Total tapped Si (kg) & 6,900 \\
\hline Fine Si addition $(\mathrm{kg})$ & 100 \\
\hline Flux addition (kg) & 215 \\
\hline Gas rate $\left(\mathrm{Nm}^{3} / \mathrm{min}\right)^{\mathrm{a}}$ & 3.7 \\
\hline Tapping time (min) & 120 \\
\hline Gas-blowing time (min) & 130 \\
\hline
\end{tabular}

elements. ${ }^{10}$ As a result of these errors, the numerical evaluation of the data for these elements would not be reliable and they will only be discussed in a limited manner. Two types of analytical errors were used to separate reliable from less reliable data: the instrumental detection limit (IDL) and the relative standard deviation (RSD) from the ICP-MS analysis. The elements with less reliable data, i.e., large analytical errors, were either present in concentrations below the IDL or had an RSD of the analysis values larger than $10 \%$. In fact, most elements in this category were affected by both of these errors.

A recovery interval was calculated for all 62 elements in this study using the concentration interval limits in the mass flows into and out of the ladle. For all elements, the recovery interval included $100 \%$.

Figures 6 and 7 show the distribution of the elements into and out of the ladle, respectively. The distribution is given in wt.\%. Note that the mass of the fume is much smaller than the mass of the condensed phases in Fig. 7. When comparing with Fig. 2, please note that the raw Si from the furnace is the tapped Si going into the ladle.

\section{The Ladle Fume}

An overview of the distribution of elements in the ingoing and outgoing material flows are found in Figs. 6 and 7. It can be observed that, as predicted by the boiling point model, most elements are found in the condensed phases but many of the elements that are expected to go to the fume also remain in the melt. Only $\mathrm{Pb}, \mathrm{Mg}$, and $\mathrm{Zn}$ are predominant in the fume. However, when interpreting the figure, it should be kept in mind that the distribution values in the figures are calculated by mass and the masses of the slag and refined silicon are very large compared with the mass of the fume. Also, the amount of fume is difficult to estimate with high accuracy and hence has a larger measurement error. ${ }^{10}$

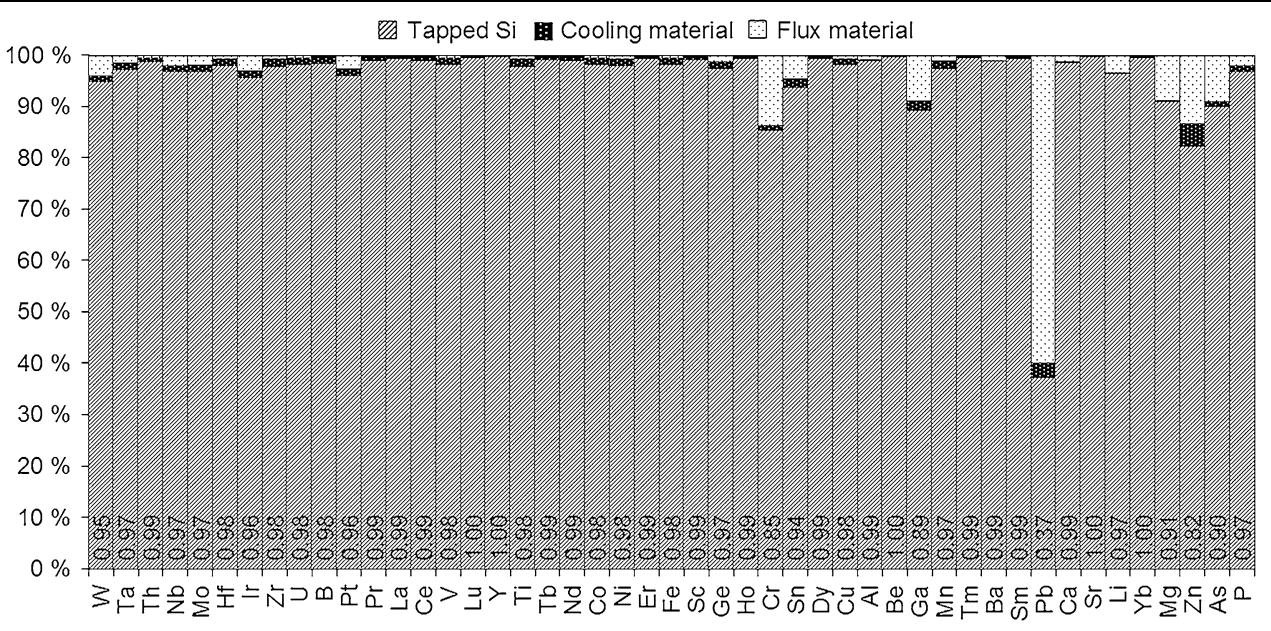

Fig. 6. Distribution of elements in the mass flows into the refining ladle: tapped $\mathrm{Si}$, the cooling material, and the flux material. The distribution fractions of the tapped silicon are included at the base of each column. 


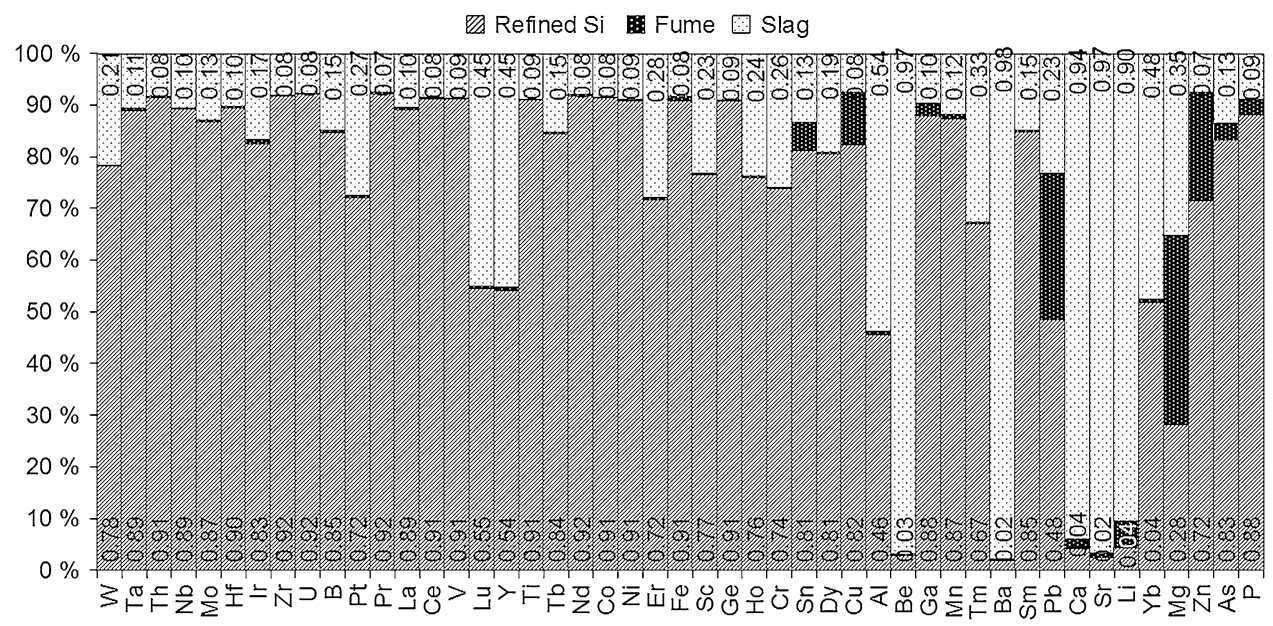

Fig. 7. Distribution of elements in the mass flows out of the refining ladle: refined $\mathrm{Si}$, the slag, and the fume. The distribution fractions for the refined silicon and the slag are displayed in each column, at the base and at the top, respectively. The distribution is given in mass\%. Please note that the mass of the fume is much smaller than the mass of the condensed phases.

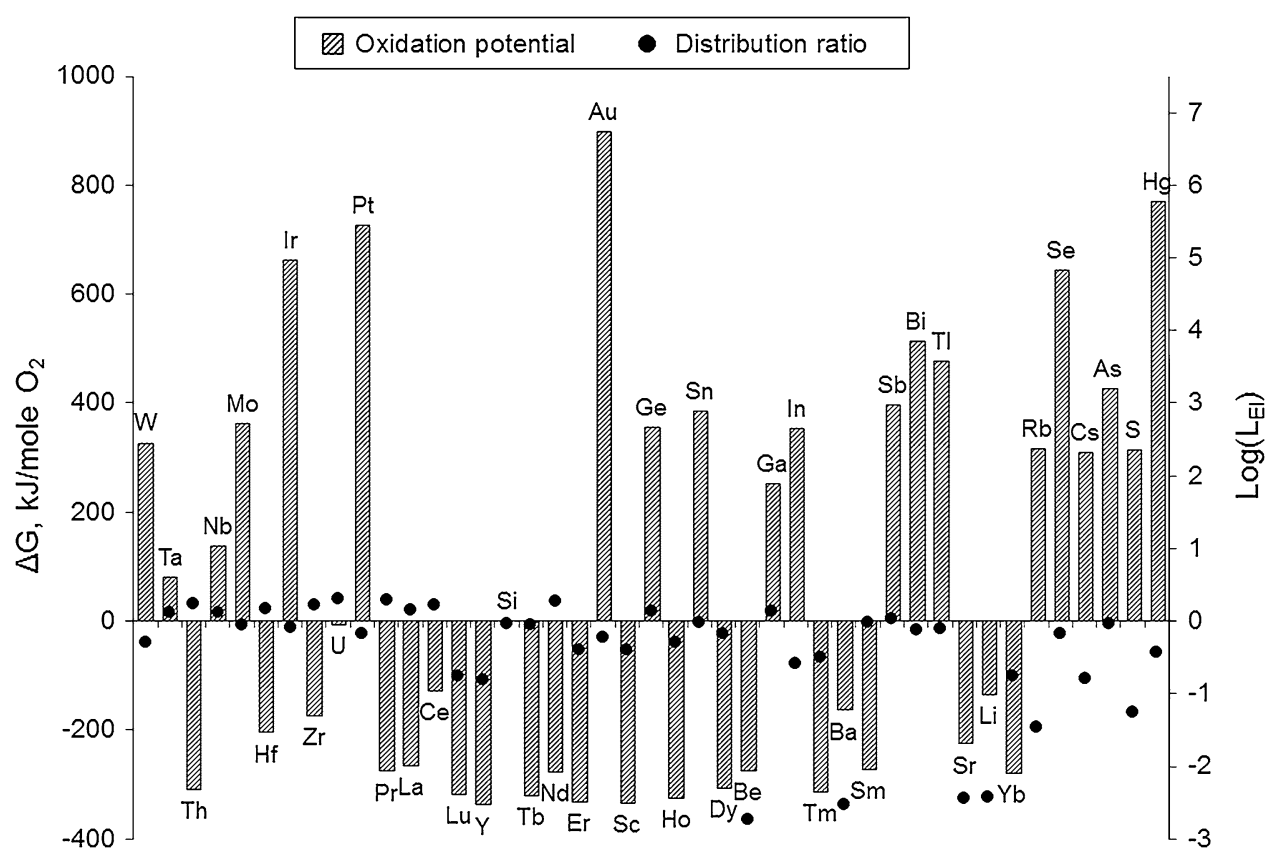

Fig. 8. Experimental distribution ratio between the condensed phases (filled circle) compared with the relative Gibbs free energy of oxidation of the elements that could not be modeled. Note the logarithmic scale on the right-hand side.

If the fume concentrations in Table II are interpreted in combination with Figs. 3 and 7 , the results confirm that most elements expected to be in the fume have relatively high measured concentrations in the fume. $\mathrm{Li}, \mathrm{Sr}, \mathrm{Ca}$, and $\mathrm{Yb}$ do not, however, primarily go to the fume as may be expected by their low boiling points. These elements form stable oxides and their oxides have higher boiling points; therefore they report to slag to a large extent. $\mathrm{Cu}, \mathrm{Sn}$, and $\mathrm{Pb}$, on the other hand, are expected to remain in the melt but display high concentrations in the fume, which may be explained by their high vapor pressures and positive deviation from ideality $(\mathrm{Sn}, \mathrm{Pb})$ in $\mathrm{Si}^{12}$
In Table II, the concentration values obtained for $\mathrm{Bi}$, Se, Cd, Tl, In, and Ag have large analytical errors (IDL and RSD) in the condensed phases, but the concentrations in the fume are relatively high and the reliability of the values in the fume are therefore good. Thus, it is concluded that these elements tend to accumulate in the fume. The ideal-behavior-based boiling point model predicts this scenario for Se, Cd, and $\mathrm{Tl}$, while $\mathrm{Bi}$, In, and $\mathrm{Ag}$ are expected to stay in the condensed state. $\mathrm{Bi}$, $\mathrm{Ag}$, and In have, however, higher vapor pressures than $\mathrm{Si}$ at $1,500^{\circ} \mathrm{C}$ and show positive deviation from ideality. ${ }^{12}$ 


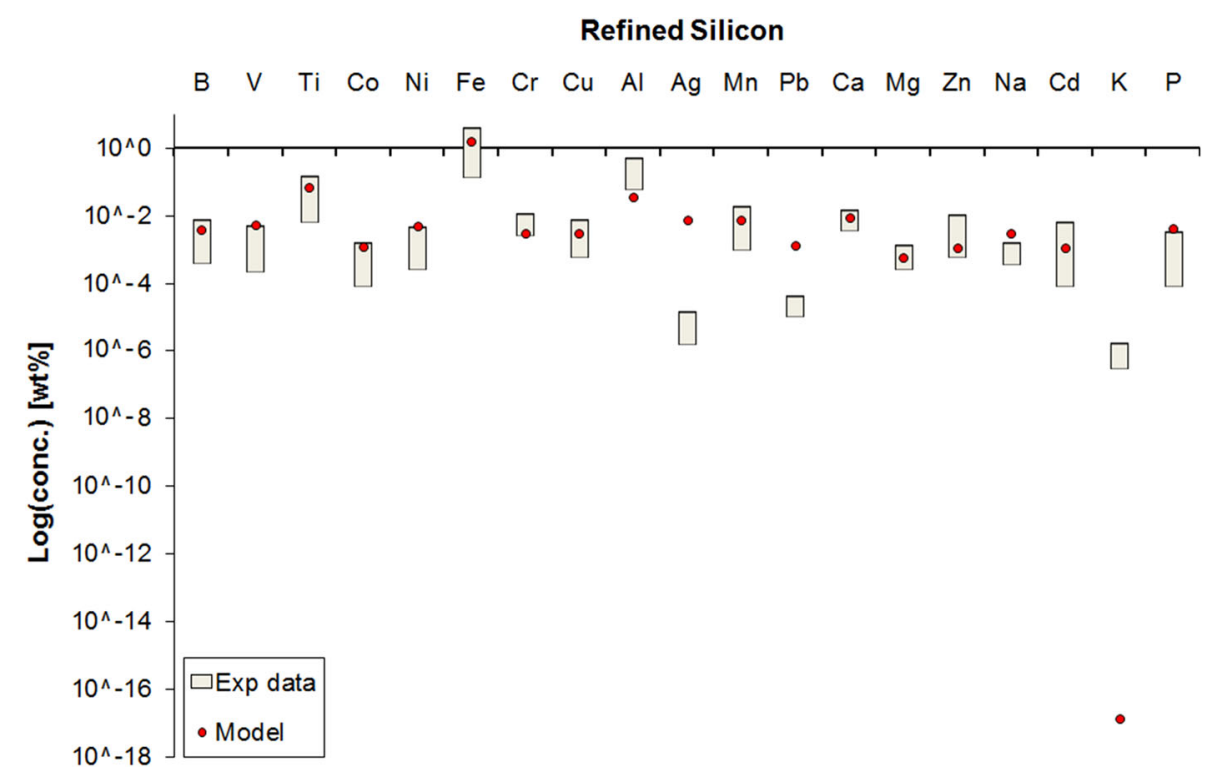

Fig. 9. Comparison of modeled and experimental concentrations of 19 elements in the molten, refined Si product. Note the logarithmic $y$-axis.

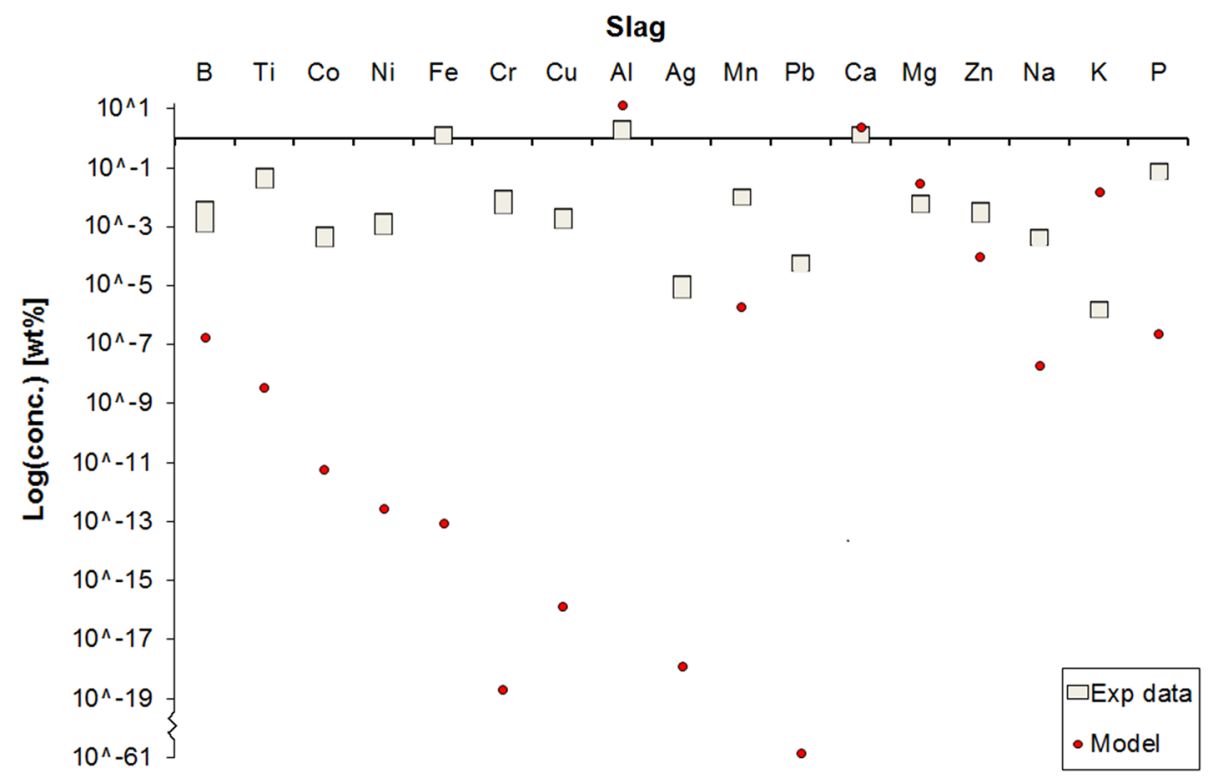

Fig. 10. Comparison of modeled and experimental concentrations of 17 elements in the slag phase. Note the broken, logarithmic $y$-axis.

The results for elements with large analytical errors in all outgoing phases are inconclusive; these are $\mathrm{Ir}, \mathrm{Pt}, \mathrm{S}, \mathrm{Hg}$, and $\mathrm{Cs}$. (A more detailed discussion on these errors can be found in a separate publication. ${ }^{10}$ ) These elements tend to be removed from the silicon phase in the furnace via the exhaust gas and silica fume ${ }^{8}$ and their concentrations are too low to detect in the ladle. These elements have high vapor pressure $^{12}$ and are therefore likely to vaporize from the ladle as well. Elements with similar vapor pressure (higher than $\mathrm{Si}$ at $1,500^{\circ} \mathrm{C}$ ) and furnace behavior (they typically vaporize) that are detectable in the ladle include $\mathrm{K}, \mathrm{Cd}, \mathrm{Na}, \mathrm{Mg}, \mathrm{Zn}$, and $\mathrm{Pb}$. They all report to the ladle fume.
Most notable differences in furnace and ladle fume are found for $\mathrm{Li}$ and $\mathrm{Sr}$; according to Garcia and Myrhaug, ${ }^{8}$ they vaporize from the furnace, but in the ladle, they report to the slag instead. Some elements evaporate from both the furnace and the ladle but are reintroduced into the ladle with the flux. Therefore, $\mathrm{Pb}, \mathrm{Zn}$, and As still occur in the refined product.

\section{The Slag Refining}

Unless large deviations from ideality are displayed, the elemental distribution between silicon and slag is expected to depend primarily on the 


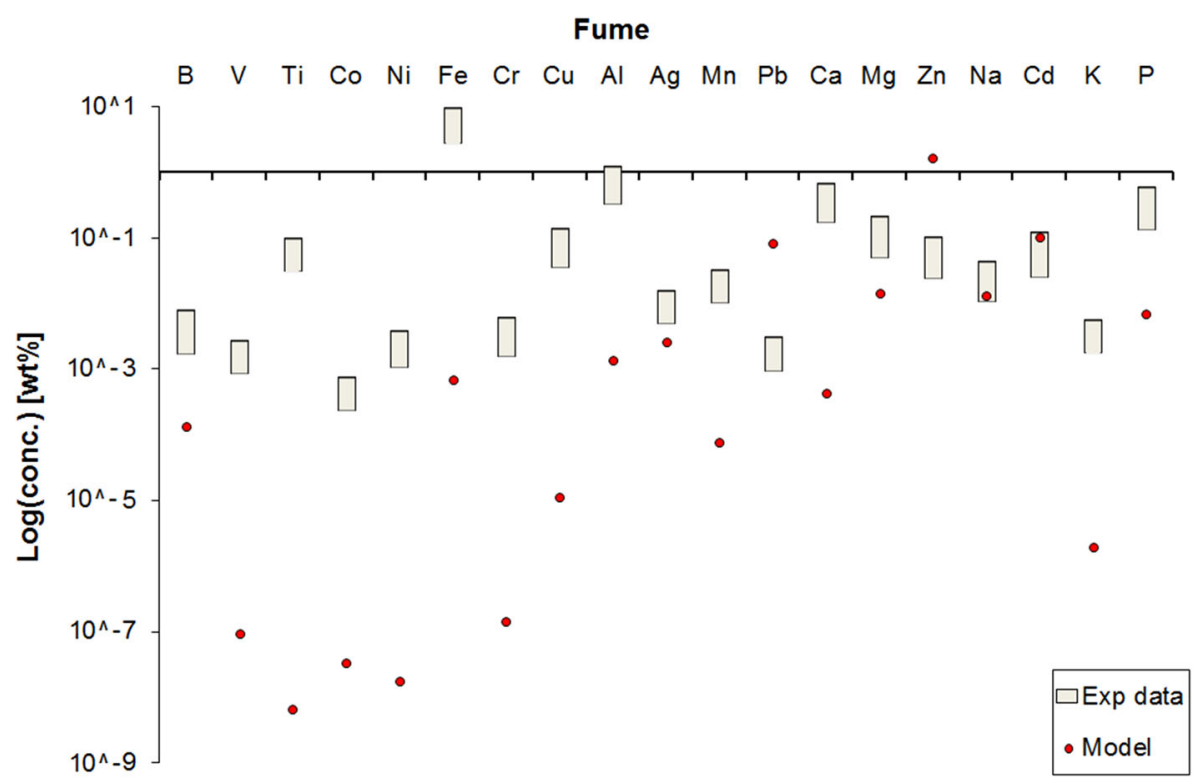

Fig. 11. Comparison of modeled and experimental concentrations of 19 elements in the fume (gas phase). Note the logarithmic $y$-axis.

oxidation potential of the elements at the process temperature. Elements with a large driving force for oxidation are expected to be predominantly found in the slag. The oxidation potentials for the elements in this system are shown in Fig. 4. It can be observed from this figure in combination with Table II and Fig. 7 that most elements with more stable oxides than $\mathrm{SiO}_{2}$ are primarily found in the slag, as expected.

The tapped $\mathrm{Si}$ is the primary material going into the ladle, and most elements primarily found in the tapped silicon tend to remain in the silicon phase, as would be expected from the boiling point model, especially because the process temperature in the ladle is lower than in the furnace. Some of these elements respond readily to the refining treatment and transfer to a large degree to the slag phase in the ladle; these are, for example, $\mathrm{Ca}, \mathrm{Al}, \mathrm{Ba}, \mathrm{Be}, \mathrm{Sr}$, $\mathrm{Yb}$, and $\mathrm{Li}$. Other elements respond poorly to the refining treatment and transfer only partly to the slag. Elements predominant in the refined product include $\mathrm{Ge}, \mathrm{Co}, \mathrm{Ce}, \mathrm{Ni}, \mathrm{Ti}, \mathrm{U}, \mathrm{V}$, and $\mathrm{Zr}$.

As thermodynamic data for many trace elements in this complex system are not readily available, their deviation from ideality is evaluated only with respect to the oxidation potential. Figure 8 shows the relative Gibbs free energy of oxide formation for the elements that could not be modeled ${ }^{13}$ compared with the experimental distribution ratio between the condensed phases, $L_{E l}^{\text {exp }}$, calculated from Eq. 6 . The deviation from ideality is found for elements such as $\mathrm{W}, \mathrm{U}, \mathrm{Ho}$, and $\mathrm{Ba}$, where the distribution ratio values (black dots) are on the opposite side of the $x$-axis compared with the oxidation potential.

Here, most elements with Gibbs free energies of oxidation higher than that of $\mathrm{Si}$ remain in the refined $\mathrm{Si}$ as expected, except $\mathrm{Se}, \mathrm{In}, \mathrm{Bi}$, and $\mathrm{Rb}$, which are primarily found in the fume. Some elements with lower Gibbs free energies of oxidation are primarily found in the slag as expected ( $\mathrm{Lu}, \mathrm{Y}, \mathrm{Be}, \mathrm{Ba}$, etc.), whereas many remain in the silicon $(\mathrm{Zr}, \mathrm{U}, \mathrm{Ce}, \mathrm{Nd}$, etc.). It is likely that the activities in liquid silicon for these elements are very low.

\section{Comparison of Modeled and Experimental Results}

Figures 9, 10, and 11 show the concentrations of the modeled elements for the refined silicon, the slag, and the fume, respectively, compared with the experimental results. Please note the logarithmic $y$-axis in these figures. The model estimates that 6,629 -kg Ref-Si is obtained after about $130 \mathrm{~min}$ of gas treatment. The modeled process produces 885 $\mathrm{kg}$ slag (including solid $\mathrm{SiO}_{2}$ ) and 376-kg off-gas. If $\mathrm{N}_{2}$ is excluded from the off-gas, the modeled amount of fume is $59 \mathrm{~kg}$, which is close to the average of $\sim 50$-kg fume measured in the plant investigation.

The correlation for modeled element concentrations in the refined $\mathrm{Si}$ is good for most elements; 14 of 19 model concentrations fall within the corresponding experimental range and another two are in the same order of magnitude. The largest difference is found for $\mathrm{K}$, for which the theoretical concentration is much lower than the experimental result. In the slag phase, however, only $\mathrm{Ca}$ falls within the experimental range. $\mathrm{Al}$ and $\mathrm{Mg}$ are of the experimental order of magnitude. As the experimental data reported are the average concentrations in top, bottom, and side slag observed as one phase, inhomogeneities between these phases make accurate slag/metal distribution determination a challenge. As such, data from the silicon analysis is more reliable. As such, experimental data from the silicon analysis are more reliable and the information available in databases is more extensive. 
Additionally, kinetic factors, which have not been included in the current analysis, may be influencing the refining process and the system may be far away from equilibrium for several elements.

In the gas phase/fume $\mathrm{Na}$ and $\mathrm{Cd}$ are the only modeled elements with concentrations within the experimental range. The evaporation of impurities from silicon metal is likely controlled by kinetic factors, rather than by thermodynamic. Therefore, it is expected that the discrepancies between equilibrium calculations and measured values for fume are relative large. As such, intermittent sampling during a refining cycle will not give time-independent, representative flux of an element. Fume sampling at the start and end of a refining cycle may give the range of element concentrations in the fume. Nonetheless, as experimental data are the foundation for most thermochemical models available today, these results indicate a need for more and better data that can improve the databases for future modeling.

\section{CONCLUSIONS}

The element distribution throughout the oxidative ladle refining of $\mathrm{MG}-\mathrm{Si}$, with respect to the mass flows into and out of the ladle, has been established. The distribution of elements between the condensed phases and fume is generally in accordance with the boiling point model. Exceptions include $\mathrm{Bi}, \mathrm{Ag}, \mathrm{In}, \mathrm{Sn}, \mathrm{Li}, \mathrm{Yb}$, and $\mathrm{Sr}$, where $\mathrm{Li}, \mathrm{Yb}$, and $\mathrm{Sr}$ should go to the fume but are readily oxidized and therefore primarily found in the slag.

Although some significant differences between the element distributions in the furnace and the ladle have been established, most elements that report to exhaust gas or silica from the furnace top are also found primarily in the fume from the ladle. Many of these elements have high vapor pressures. Elements that primarily report to the fume include $\mathrm{Ag}, \mathrm{Sn}, \mathrm{Se}, \mathrm{Cd}, \mathrm{In}, \mathrm{Bi}, \mathrm{Ag} \mathrm{Pb}, \mathrm{Zn}$, and $\mathrm{Mg}$.

The distribution of elements between the slag and the silicon is related to the oxidation potential of the elements. Most elements with a Gibbs free energy of oxidation that is more negative than that of $\mathrm{Si}$ tend to be oxidized and therefore readily refined. Conversely, elements with very low concentrations and apparent activities in the ladle (such as Th, Sm, Tm, $\mathrm{Dy}$, and $\mathrm{Tb}$ ) do not oxidize and will remain in the refined product. Elements primarily found in the slag include $\mathrm{Ca}, \mathrm{Al}, \mathrm{Li}, \mathrm{Be}, \mathrm{Ba}, \mathrm{Sr}$, and $\mathrm{Yb}$.

To our knowledge, this publication is the first of its kind to account for the elemental distribution of both major and trace elements in the OLR process. This information is useful to the silicon producing industry as it provides a detailed description of the pathway of each element through the OLR. In particular, fume concentrations are vital to enable correct estimations of the fugitive emissions from a silicon plant.

Thermochemical simulations have been performed for several elements, and the modeled con- centrations are compared with measured values. The large discrepancies in the slag and fume shows that more thorough experimental data are needed for a more fundamental understanding of the thermodynamics in such a multiphase, multicomponent system. Furthermore, there is no or very limited data available for many of the trace elements, and therefore, detailed and reliable simulations are not possible until the thermodynamic databases can be expanded.

\section{ACKNOWLEDGEMENTS}

The financing of this work was provided by the Norwegian Research Council and FFF (Norwegian Ferroalloy Producers Research Association) through the FUME project (Fugitive emissions of Materials and Energy). We would like to express our appreciation to SINTEF for their contribution to this work; to Elkem AS for allowing the measurements at their plant in Salten; and particularly to Vegar Andersen for helping with sampling. We also appreciate Norsk Elektro Optikk AS for providing equipment and technical assistance during the measurements.

\section{OPEN ACCESS}

This article is distributed under the terms of the Creative Commons Attribution License which permits any use, distribution, and reproduction in any medium, provided the original author(s) and the source are credited.

\section{REFERENCES}

1. A. Schei, J.K. Tuset, and H. Tveit, Production of High Silicon Alloys, 1st ed. (Trondheim: TAPIR Forlag, 1998).

2. W.C. Wedberg, E. Dingsøyr, and M. Dåstøl, 5th European Symposium Particle Characterization, Nürnberg, Germany (1992).

3. M.K. Næss, G. Tranell, J.E. Olsen, N.E. Kamfjord, and K. Tang, Oxid. Met. 78, 239 (2012).

4. J.E. Olsen, M. Næss, and G. Tranell, 8th International Conference on CFD in Oil \& Gas-Metallurgical and Process Industries (Trondheim: SINTEF/NTNU, 2011).

5. N. Englert, Toxicol. Lett. 149, 235 (2004).

6. A. Hobbesland, H. Kjuus, and D.S. Thelle, Scand. J. Work Environ. Health 23, 342 (2012).

7. H. Laier Johnsen, V. Søyseth, and S.M. Hetland, Int. Arch. Occup. Environ. Health 81, 451 (2007).

8. M. Garcia and E.H. Myrhaug, Elkem Silicon: Oslo, Norway. Elkem Report, 2007.

9. E.H. Myrhaug and H. Tveit, 58th Electric Furnace Conference (Orlando, FL, 2000).

10. M.K. Næss, I. Kero, and G. Tranell, JOM 65, 997 (2013).

11. W.M. Haynes, Handbook of Chemistry and Physics; Internet version 2013, 93rd ed. (Boca Raton, FL: CRC Press, 2013).

12. A. Roine, Software Manual (Pori: Outotec Research OY, 2010).

13. P. Bakke and O.S. Klevan, Process Technology Conference. Ladle Processing: Metallurgy and Operations (Orlando, FL, 1995).

14. M.D. Johnston and M. Barati, Sol. Energy Mater. Sol. Cell 94, 2085 (2010).

15. M.D. Johnston, M. Barati, and J. Non-Cryst, Solid 357, 970 (2011).

16. Chemsheet, Software. http://gtt.mch.rwth-aachen.de/gttweb/chemsheet. Accessed 4 Apr 2013. 
17. K. Tang, Unpublished additional data (Trondheim: SINTEF Materials and Chemistry. Proprietary database, 2013).

18. K. Tang, E.J. Ovrelid, and G. Tranell, Mater. Trans. JIM 50, 1978 (2009).
19. FactSage TM $^{\mathrm{TM}}$, Online database. http://www.crct.polymtl.ca/fact/ documentation/FToxid/FToxid_Figs.htm. Accessed 16 Dec 2009.

20. H. Gaye, J. Lehmann, T. Matsumiya, and W. Yamada, 4th International Conference on Molten Slags and Fluxes (Sendai: ISIJ, 1992). 